\title{
STUDY OF INFLUENCE OF BODY ADIPOSITY ON INSULIN RESISTANCE IN PCOS
}

\author{
Prathiba S1, Girijasivam S. P2, Ravi Shankar N³
}

${ }^{1}$ Assistant Professor, Department of Physiology, Chengalpattu Medical College, Tamilnadu.

${ }^{2}$ Assistant Professor, Department of Physiology, Chengalpattu Medical College, Tamilnadu.

${ }^{3}$ Assistant Professor, Department of Medicine, Chengalpattu Medical College, Tamilnadu.

\section{ABSTRACT}

\section{BACKGROUND}

PCOS is a most common metabolic endocrine disorder affecting women of reproductive age group. Prevalence of obesity and overweight is observed more in patients with PCOS. The exact cause of PCOS remains unknown till now. Insulin resistance is considered to be a prime factor in the pathogenesis of PCOS. Insulin resistance may present in PCOS independent of obesity. Our study is aimed to investigate the role of adiposity with insulin resistance in patients with PCOS by evaluating the insulin resistance index in obese and non-obese PCOS patients.

\section{MATERIALS AND METHODS}

100 women with PCOS diagnosed as per Rotterdam's criteria of age 20-30 years were selected as study subjects for this crosssectional study. They were divided into 2 groups as obese and non-obese PCOS based on BMI. Fasting insulin, fasting glucose and fasting total cholesterol were measured. HOMA-IR was calculated with these values. Statistical analysis was done using student ' $\mathrm{t}$ ' test SPSS version 17.

\section{RESULTS}

Fasting blood sugar differed significantly and highly significant difference was obtained in fasting insulin and HOMA-IR values among the study groups.

\section{CONCLUSION}

Although, high HOMA-IR values ( $>2.5$ ) were observed in both obese and non-obese PCOS groups, significantly higher values were obtained in obese PCOS group. Body adiposity aggravates insulin resistance in PCOS patients.

\section{KEYWORDS}

PCOS, Obesity, Insulin Resistance, HOMA-IR.

HOW TO CITE THIS ARTICLE: Prathiba S, Girijasivam SP, Shankar RN. Study of influence of body adiposity on insulin resistance in PCOS. J. Evolution Med. Dent. Sci. 2016;5(94):6906-6908, DOI: 10.14260/Jemds/2016/1563

\section{BACKGROUND}

PCOS is a highly prevalent metabolic endocrinopathy affecting women belonging to reproductive age group.(1) The exact aetiology of PCOS remains unknown. It affects $2.2-26 \%$ of Indian females.(2) Patients with PCOS are presenting clinically with symptoms related to anovulation, menstrual cycle disturbances, hyperandrogenism.(3) Most of the patients with PCOS are also overweight (BMI $>25 \mathrm{~kg} / \mathrm{m}^{2}$ ) or obese (BMI > $30 \mathrm{~kg} / \mathrm{m}^{2}$ ). In addition to these manifestations, they have features of abnormal glucose metabolism.(4) Recently, hyperinsulinaemia, insulin resistance is found to be important factor in the pathogenesis of PCOS.(5) Insulin resistance is thought to be predominant factor in the association between glucose intolerance, obesity, lipid abnormalities, hypertension and coronary artery disease.(6) Insulin resistance may present in PCOS independent of obesity.(7) Insulin resistance accentuated by obesity results in marked exacerbation of all the features of PCOS.(5)

Financial or Other, Competing Interest: None.

Submission 19-10-2016, Peer Review 13-11-2016,

Acceptance 18-11-2016, Published 23-11-2016.

Corresponding Author:

Dr. Prathibas,

Department of Physiology,

Chengalpattu Medical College,

Chengalpattu, Tamilnadu,

India.

E-mail: spgirijasivam@gmail.com

DOI: $10.14260 /$ jemds $/ 2016 / 1563$

\section{(c) $($ ) $\$$}

Therefore, the present study is aimed to measure the insulin resistance index in obese and non-obese PCOS patients and study the relationship of adiposity with insulin resistance in PCOS patients.

\section{MATERIALS AND METHODS}

This cross-sectional study was performed from June 2015 to December 2015 in Chengalpattu Medical College Hospital after obtaining the permission from Institutional Ethics Committee; 100 females in the age group 20 - 30 years diagnosed as PCOS with Rotterdam's criteria were participated in this study after taking their informed consent. (8) They were divided into two groups based on BMI. Patients with BMI $<25 \mathrm{~kg} / \mathrm{m}^{2}$ were included in non-obese PCOS and patients with BMI $>25 \mathrm{~kg} / \mathrm{m}^{2}$ were included in obese PCOS group.(9)

\section{Inclusion Criteria}

100 patients diagnosed as PCOS with Rotterdam's criteria of the age between 20 - 30 years were considered to be study subjects for this study.

\section{Exclusion Criteria}

PCOS patients with confounding factors, which influence the insulin resistance like pregnancy, breast feeding, Diabetes mellitus, Hormone therapy and with Endocrine disorders like congenital adrenal hyperplasia, hypothyroidism, etc. were excluded from the study. 
Body mass index was calculated from the anthropometric data of study subjects using the formula: $\mathrm{BMI}=$ weight in $\mathrm{kg} /$ height in metre. ${ }^{2}$ Under aseptic precautions, $5 \mathrm{~mL}$ blood was collected from the study subjects after $10 \mathrm{hrs}$. of fasting. Fasting plasma glucose was measured by glucose oxidaseperoxidase method. Fasting serum insulin levels was estimated using Chemiluminescent immunometric assay. Serum cholesterol was also measured using CHOD PAP method. HOMA-IR (Homeostatic model assessment Insulin resistance) is a new method to quantify the insulin resistance and given by, ${ }^{(10)}$

HOMA-IR = Fasting glucose X Fasting Insulin 405

The statistical analysis of the data was done using the Statistical Package for Social Sciences software version 17.

\section{RESULTS}

The mean and standard deviation of the variables were measured for both the groups. Independent student ' $t$ ' test was applied as test of significance at $95 \%$ confidence interval. $\mathrm{P}$ value $<0.05$ is considered as significant. The results were given in Table I and II.

\begin{tabular}{|c|c|c|c|}
\hline Variable & $\begin{array}{c}\text { Non-Obese } \\
\text { PCOS } \\
\text { (mean } \pm \text { SD) }\end{array}$ & $\begin{array}{c}\text { Obese } \\
\text { PCOS } \\
\text { (mean } \pm \text { SD) }\end{array}$ & $\begin{array}{c}\text { P } \\
\text { Value }\end{array}$ \\
\hline Age (years) & $20.92 \pm 1.16$ & $21.3 \pm 1.75$ & 0.2 \\
\hline $\begin{array}{c}\mathrm{BMI} \\
\left(\mathrm{kg} / \mathrm{m}^{2}\right)\end{array}$ & $22.4 \pm 1.35$ & $27.8 \pm 0.83$ & $\begin{array}{c}< \\
0.001^{* *}\end{array}$ \\
\hline $\begin{array}{c}\text { Serum } \\
\text { Cholesterol } \\
(\mathrm{mg} / \mathrm{dL})\end{array}$ & $173.52 \pm 17.16$ & $207.72 \pm 15.14$ & $\begin{array}{c}< \\
0.001^{* *}\end{array}$ \\
\hline
\end{tabular}

Table 1. Comparison of Age, BMI, Serum Cholesterol between Obese and Non-Obese PCOS

$\mathrm{P}<0.05$ : significant; $\mathrm{P}<0.001^{* *}$ : Highly significant.

Table I-shows the comparison of age, BMI and serum cholesterol values between obese and non-obese PCOS. There was no significant difference in age among the study groups. Both BMI and serum cholesterol values differed significantly between the study subjects.

\begin{tabular}{|c|c|c|c|}
\hline Variable & $\begin{array}{c}\text { Non-Obese } \\
\text { PCOS } \\
\text { (mean } \pm \text { SD) }\end{array}$ & $\begin{array}{c}\text { Obese } \\
\text { PCOS } \\
\text { (mean } \pm \text { SD) }\end{array}$ & P Value \\
\hline $\begin{array}{c}\text { Fasting } \\
\text { Blood Sugar } \\
\text { (mg/dL) }\end{array}$ & $78.36 \pm 4.77$ & $80.96 \pm 6.4$ & 0.02 \\
\hline $\begin{array}{c}\text { Fasting } \\
\text { Insulin } \\
(\mu \mathrm{IU} / \mathrm{mL})\end{array}$ & $23.4 \pm 4.65$ & $26.22 \pm 2.92$ & $<0.001^{* *}$ \\
\hline HOMA - IR & $4.52 \pm 0.92$ & $5.37 \pm 0.7$ & $<0.001^{* *}$ \\
\hline \multicolumn{4}{|c|}{ Table 2. Comparison of Fasting Blood Sugar, Fasting } \\
Insulin, HOMA-IR Values \\
\hline
\end{tabular}

$\mathrm{P}<0.05$ : significant; $\mathrm{P}<0.001^{* *}$ : Highly significant.

Table II - shows the comparison of fasting blood sugar, fasting insulin and HOMA-IR values. There was significant difference seen with fasting blood sugar values. Highly significant difference was observed with fasting insulin and HOMA-IR values.

\section{DISCUSSION}

PCOS is one of the most frequent metabolic endocrine disorder characterised by menstrual irregularities, biochemical and clinical hyperandrogenism. Abnormal glucose metabolism, hyperinsulinaemia and insulin resistance are considered to be closely linked with PCOS that correlates with increased cardiovascular risk in PCOS independent of obesity.(11) Prevalence of obesity and overweight is higher in PCOS patients.(12) Interplay of abnormal glucose metabolism and body adiposity exacerbates the clinical course of PCOS.(13) Hence, this study was performed to establish the influence of body adiposity on glucose metabolism and insulin resistance in PCOS patients, which may throw a light in novel therapeutic approach in PCOS.

Various pathogenic mechanism have been proposed for this heterogeneous disorder PCOS. Recent theories have focused on a major role of insulin resistance, hyperinsulinaemia and altered lipid profile in the pathogenesis of PCOS. $(5,14)$

Overweight and obesity is observed in many women with PCOS. Severe hyperandrogenism and its associated clinical features like hirsutism, menstrual irregularity (anovulation) have been reported in patients with PCOS. Insulin resistance is said to be the predominant coupling factor in the association between hypertension, glucose intolerance, obesity, lipid abnormalities and CAD. $(14,5)$

Insulin resistance in PCOS is described by reduced sensitivity to insulin in peripheral tissues, especially muscle and adipose tissue but not in liver. Hyperinsulinaemia in PCOS reflects the hypersecretion of insulin alone rather than of proinsulin and its split products.(15) Defect in insulin-induced inhibition of lipolysis is also seen in PCOS patients.(16) Obesity and insulin resistance go hand in hand. HOMA-IR is one of the reliable method in assessing the insulin resistance.

In our study, there was significant difference observed in fasting glucose values between obese and non-obese PCOS patients with a $P$ value of 0.02 . Similar results were also found in MI Mahmoud et al, Kaviprasanna et al and Agarwal $\mathrm{N}$ et al. $(5,17,18)$ Even though blood sugar values are within normal limits, they are relatively high in obese PCOS group. The onset of absolute glucose intolerance is seen at age between $30-40$ years.(19) The mean age of both study group in our study is very much less that supports the normal glucose values obtained in this study.

High fasting insulin values are obtained for both obese and non-obese PCOS patients, which differed with a P value of < 0.001 . These values were in accordance with Sudha et al, MI Mahmoud et al, Kaviprasanna et al and Agarwal N et al.(5,17,18,20) It was proved that occurrence of hyperinsulinaemia in PCOS is independent to the presence of obesity.(21) In spite of it, more than $20 \%$ of obese PCOS patients have increased blood sugar values and fasting insulin values than normal population.

Highly significant difference was observed with a $P$ value of $<0.001$ in insulin resistance index (HOMA-IR) values between obese and non-obese PCOS. Similar values are also seen in Sudha et al, MI Mahmoud et al, Kaviprasanna et al and Agarwal N et al. $(5,17,18,20)$ Higher HOMA-IR values in obese PCOS patients states that adiposity plays a role not only in the development of PCOS, but also in the maintenance of clinical features of PCOS. Thus, body adiposity strongly influences the severity of its clinical, metabolic and endocrine features in patients with PCOS. 
Body adiposity strongly accentuates the reproductive, clinical and metabolic changes associated with PCOS.(22) Insulin resistance play a role in the development of dyslipidaemia in PCOS patients. Hyperinsulinaemia and insulin resistance shows direct relation with cardiovascular risk factor in PCOS. Therefore, it is recommended that appropriate screening and management of insulin resistance and dyslipidaemia might prevent cardiovascular risk and metabolic morbidity in PCOS patients.

\section{ACKNOWLEDGEMENT}

We would like to express our sincere thanks to all the women who participated in this study.

\section{REFERENCES}

1. Xiang SK, Hua F, Tang Y, et al. Relationship between serum lipoprptein ratios and insulin resistance in polycystic ovary syndrome. International Journal of Endocrinology 2012;2012:173281.

2. Nidhi R, Padmalatha V, Nagarathna R, et al. Prevalence PCOS in Indian adolescents. J Paediatric Adoloscence Gynaecol 2011;24(4):223-7.

3. Zawadzki JK, Dunaif A. Diagnostic criteria for polycystic ovary syndrome: towards a rational approach. In: Dunaif A, Givens JR, Haseltine FR, et al. eds. Polycystic ovary syndrome. Oxford, England: Blackwell Scientific 1992: 377-84.

4. Dokras A, Bochner M, Hollinrake E, et al. Screening women with polycystic ovarian syndrome for metabolic syndrome. Obstet Gynaecol 2005;106(1):131-7.

5. Mahmoud MI, Habeeb F, Kasim K, et al. Reproductive and biochemical changes in obese and non obese PCOS. Alexandria Journal of Medicine 2015;51:5-9.

6. Apridonidze T, Essah PA, Luorno MJ, et al. Prevalence and characteristics of the metabolic syndrome in women with polycystic ovary syndrome. J Clin Endocrinol Metab 2005;90(4):1929-35.

7. Shanik MH, Xu Y, Skrha J, et al. Insulin resistance and hyperinsulinemia. is hyperinsulinemia the cart or the horse? Diabetes Care 2008;31(Suppl 2):S262-8.

8. The Rotterdam ESHRE/ASRM-Sponsored PCOS consensus Workshop Group. Revised 2003 consensus on diagnostic criteria and long-term health risks related to polycystic ovary syndrome. Fertil Steril 2004;81(1):19-25.

9. American College of Obstetricians and Gynecologists. ACOG practice bulletin. Polycystic ovary syndrome. Number 41, December 2002. Int J Gynaecol Obstet 2003;80(3):335-48.
10. Wallace TM, Levy JC, Matthews DR. Use and abuse of HOMA modeling. Diabetes Care 2004;27(6):1487-95.

11. Mather KJ, Kwan F, Corenblum B. Hyperinsulinemia in polycystic ovary syndrome correlates with increased cardiovascular risk independent of obesity. Fertil Steril 2000;73(1):150-6.

12. Bulun SE, Adashi EY. The physiology and pathology of the female reproductive axis. In: Kronenberg HM, Melmed S, Polonsky KS, Larsen PR. eds. Williams textbook of endocrinology. Chapter 17. 12 $2^{\text {th }}$ edn. Philadelphia, PA: Saunders Elsevier 2011.

13. Sam S. Obesity and PCOS. Obes Manag 2007;3(2)69-73.

14. Kalra A, Nair S, Rai L, et al. Association of obesity \& insulin resistance with dyslipidemia in Indian women with PCOS. IJMS 2006;60(11):447-53.

15. Franks S. Polycystic ovary syndrome. N Engl J Med 1995;333(13):853-61.

16. Poretsky L, Cataldo NA, Rosenwaks Z, et al. The insulinrelated ovarian regulatory system in health disease. Endocr Rev 1999;20(4):535-82.

17. Agarwal N, Gangopadhyay S, Koch N, et al. PCOS \& insulin resistance: North Indian study. Int J Res Med Sci 2015;3(6):1321-24.

18. Kaviprasanna S, Saikumar $P$, Alaguveni $T$, et al. Insulin resistance as an independent risk factor for the development of dyslipidemia in polycystic ovarian syndrome. Advances in Biological Research 2014;8(2):536. ISSN 1992-006.

19. Ehrmann DA, Barnes RB, Rosenfield RL, Cavaghan MK, Imperial J. Prevalence of impaired glucose tolerance and diabetes in women with polycystic ovary syndrome. Diabetes Care 1999;22(1):141-6.

20. Sudha A. Study of insulin resistance and lipid profile in polycystic ovarian syndrome. International Journal of Scientific and Research Publications 2016;6(2):1-5. ISSN 2250-3153.

21. Dunaif A. Insulin action in the PCOS. Endocrinol Metab Clin North Am 1999;28(2):341-59.

22. Holte J, Bergh T, Berne C, et al. Restored insulin sensitivity but persistently increased early insulin secretion after weight loss in obese women with polycystic ovary syndrome. J Clin Endocrinol Metabol 1995;80(9):2586-93. 